\title{
Refractory Hepatosplenic T-Cell Lymphoma
}

National Cancer Institute

\section{Source}

National Cancer Institute. Refractory Hepatosplenic T-Cell Lymphoma. NCI Thesaurus.

Code C153161.

Hepatosplenic T-cell lymphoma that is resistant to treatment. 